\title{
An Analysis of the Reliability and Validity of a Korean Version of the Mobility and Gait Assessment Tools for Patients with Stroke
}

\author{
Ho Young Jang', Jeong-Hoon Lee², Jung Lim Oh³, Hyun Soo Lee', Suk Min Lee ${ }^{4}$ \\ 'Department of Physical Therapy, The Graduate School, Sahmyook University; ${ }^{2}$ Department of Occupational Therapy, The Graduate School, Yonsei \\ University; ${ }^{3}$ Department of Physical Therapy, Daewon University College, ${ }^{4}$ Department of Physical Therapy, College of Health and Welfare, Sahmyook \\ University, Korea
}

Purpose: This study aimed to systematically analyze the reliability and validity of Korean versions of mobility and gait assessment tools for patients with stroke.

Methods: Two reviewers conducted an independent literature search and systematically reviewed the literature. Literature published until June of 2017 was searched using search engines for electronic databases. The 2 reviewers reviewed the title and abstract of each article. Among the articles examined, we read the full text of those judged to be suitable for our study. We classified the selected data into research methods and results. The determination was made through mutual agreement.

Results: The reviewers selected 5 articles related to the purpose of this study. The DGI was found to be moderately associated with BBS, 10MWT, and TUG in intra-rater reliability (ICC $=0.92)$, inter-rater reliability $(I C C=0.88)$, and concurrent validity tests. The FGA demonstrated a high level of reliability with intra-rater $(I C C=0.92-0.95)$ and inter-rater reliability $(I C C=0.91,0.95)$. The intra-rater reliability of the RMI was high at ICC $=0.98$. Its concurrent validity showed a high association with STREAM and BI. The intra-rater reliability of the MAS was ICC $=0.75-0.99$. Its inter-rater reliability was very high, exceeding 0.99 . The inter-rater reliability of the Tinetti-gait Scale was ICC $=0.91$, and its concurrent validity was moderately associated with the DGI, 10WMT, OLST, FM-L/E, and STS.

Conclusion: The results of this study revealed that the reliability and validity of the Korean versions of the mobility and gait assessment tools were high.

Keywords: Assessment, Gait, Mobility, Reliability, Validity

\section{서 론}

이동성과 보행 기능 회복은 뇌졸중 환자의 가장 중요한 재활 치료 목 표이며,' 다양한 신경계 손상과 근골격계 손상 환자에서도 중요한 치 료 목표이다. 보행 기능을 개선하기 위한 방법으로는 기능적 전기자 극 치료, 바이오 피드백, physical fitness training, high-intensity therapy, 반복적인 과제 특이성 훈련, 탈부하 트레드밀 보행 치료, 수중 보행 치 료, 이중과제 보행 훈련과 시각적 되먹임 로봇 보조 보행 훈련 그리고 동작관찰훈련과 함께 청각적 피드백을 적용한 훈련 등이 있다.2-7

효과적인 치료를 위해서는 환자에 대한 정확한 평가가 중요하다. 평가는 문제의 원인을 알아내고, 치료 계획을 수립하며, 결과 측정에

\section{사용된다. ${ }^{8}$}

이동성과 보행 평가도구로는 10 meter walk test (10MWT), 6 minute walk test (6MWT), timed up and go test (TUG) 같은 기능적 동작 수행 을 통한 평가(functional performance tests) 방법과 motor assessment scale (MAS), dynamic gait index (DGI), Rivermead mobility index (RMI), functional ambulation classification (FAC), functional independent measure (FIM), Chedoke-McMaster stroke assessment (CMSA) 등 과 같은 서열척도(ordinal scale)로 구성된 평가도구를 통한 평가 그리 고 운동역학적(kinetic)이나 운동형태학적(kinematic)인 방법을 활용 한 장비를 이용한 평가(instrumented measurement tools) 등의 다양한 평가 방법이 사용되고 있다.9-11 Tyson과 Connell ${ }^{12}$ 은 신뢰도와 타당도 
있고 임상적으로 유용한 이동성과 보행 평가 방법으로 5 meter walk test (5MWT)와 10 meter walk test (10MWT), 6 minute walk test (6MWT), high level mobility assessment tool (HLMAT), Rivermead mobility index (RMI) 등을 추천하고 있다.

그러나 대부분의 이동성과 보행 평가도구들이 해외에서 개발되어 사용되고 있어 언어적, 문화적 차이로 인해 국내 물리치료사들이 평 가를 위해 표준화된 평가도구를 임상에 적용하는데 어려움이 있어 한글화된 평가도구로의 번안이 필요하다.

한글화된 평가도구로의 번역 과정은 내용이 언어학적으로 정확하 게 옮겨지고, 각 나라의 문화적 특성에 맞게 구성되어, 원본의 내용적 타당성이 유지되도록 제작해야 한다. 첫 단계는 한국어가 모국어인 두 명이 독립적으로 영어에서 한국어로 순번역(forward translation) 후, 각각의 한국어 번역판을 합의버전으로 통합한다. 다음 단계로 역 번역 과정은 영어가 모국어이고 한국어와 영어를 모두 구사할 수 있 는 2 명의 번역가가 순번역 후에 만들어진 합의버전을 다시 영어로 역 번역(backward translation)한다. 최종적으로 검토위원회가 모든 버전 의 평가지를 비교 분석하여 오리지널 영어 버전과 일치하게 하여 한 국어 버전을 완성한다. ${ }^{13}$

현재 이런 과정을 통해 한글화된 이동성과 보행 평가도구들이 신 뢰도와 타당도를 검증하여 제시되고 있으나 이에 대한 체계적인 분 석이 이루어지지 않았다. 이에 본 연구의 목적은 뇌졸중 환자에 한글 화된 이동성과 보행 평가도구들의 신뢰도와 타당도를 체계적으로 분석하고 제시하여 임상에서 물리치료사들이 정확한 평가를 위해 활용하고자 한다.

\section{연구 방법}

\section{1. 연구 절차}

우리는 삼육대학교 생명윤리심의위원회(IRB)에 심의면제 승인을 받 았다.
두 명의 리뷰어는 10 년 이상의 임상 경력을 가진 물리치료사(Jang $\mathrm{HY})$ 와 작업치료사(Lee JH)로 각각 독립적으로 문헌 검색을 통해 체 계적으로 고찰 하였으며 electronic databases는 RISS, NDSL과 KISS 그 리고 DBpia를 이용해 2017년 6월 까지 출간된 문헌을 검색하였고, 검 색 key word는 "Gait or walking or ambulation or mobility", "Test or assessment or measure or outcome measure or measurement tool", "Korean version", "Reliability" 그리고 "Validity"를 영어로 검색하였다. 리뷰어들 은 각각 문헌의 제목과 초록을 검토한 후 확인 된 자료 중 연구에 적 합하다고 판단 된 문헌은 전체 문헌(full text)을 읽었다. 리뷰어들은 선 정된 자료를 연구 방법과 결과로 분류하였고 서로 합의 하에 결정하 였다(Fig. 1).

\section{2. 문헌의 포함 기준과 제외 기준}

1) 포함 기준

(1) 번안 과정을 거친 한글화된 평가도구를 가지고 있는 문헌.

(2) 평가도구에 대한 신뢰도 혹은 타당도에 대한 정보를 가지고 있 는 문헌.

2) 제외 기준

(1) 번안 과정을 거친 한글화된 평가도구를 가지고 있지 않는 문헌.

(2) 평가도구에 대한 신뢰도와 타당도에 대한 정보가 제시되어 있 지 않은 문헌

(3) 수정된 평가도구와 기능적 동작 수행을 통한 평가도구에 대한 신뢰도 혹은 타당도를 포함하는 문헌.

\section{연구 결과}

두 명의 리뷰어는 117 개 문헌의 제목과 26 개 초록을 검토한 후 확인 된 자료 중 연구에 적합하다고 판단 된 14 개 문헌은 전체 내용을 읽었 고, 본 연구의 목적에 맞는 5 개 문헌의 자료를 최종 채택했으며, 뇌졸

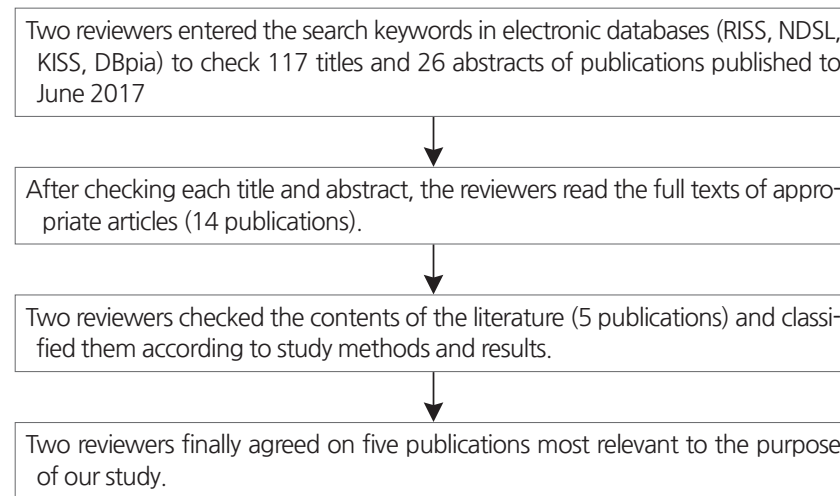

Two reviewers entered the search keywords in electronic databases (RISS, NDSL, KISS, DBpia) to check 117 titles and 26 abstracts of publications published to une 2017

After checking each title and abstract, the reviewers read the full texts of appropriate articles (14 publications)

Two reviewers checked the contents of the literature (5 publications) and classiof our study.

Figure 1. Process of the study
Full-text articles excluded (9 publications), Reason to exclude publications

- Not Korean version assessment tools (6)

- Modified assessment tools (1)

- Functional performance test (2) 
중 환자에 한글화된 이동성과 보행 평가도구들로는 dynamic gait index (DGI), functional gait assessment (FGA), Rivermead mobility index (RMI), motor assessment scale (MAS), Tinetti-gait scale가 있었으며, 각 각의 신뢰도와 타당도를 알아보았다.

\section{Dynamic gait index (DGI)}

한글화된 DGI는 26 명의 뇌졸중 환자들을 대상으로 2 명의 물리치료 사가 검사-재검사 신뢰도를 조사하기 위해 3 일에 걸쳐 1 명의 물리치 료사가 2 번의 검사를 시행하였다. 측정자간 신뢰도는 마지막 검사에 2 명의 검사자가 동시에 평가하였다. 총 점수의 검사-재검사의 신뢰도 는 0.92 로 매우 높은 신뢰도를 보여 주었고, 총 점수의 측정자간 신뢰 도는 0.88 로 매우 높은 신뢰도를 보여 주었다. 동시 타당도를 조사하 기 위해 처음 검사가 끝난 후 $10 \mathrm{MWT}, \mathrm{TUG}, \mathrm{BBS}$ 검사를 시행하였다. 한글화된 DGI는 BBS $(\mathrm{r}=0.80)$ 와 중등도의 양의 상관관계가 있었고, $10 \mathrm{MWT}(\mathrm{r}=-0.76), \mathrm{TUG}(\mathrm{r}=-0.79)$ 와는 음의 상관관계가 있었다..$^{14}$

\section{Functional gait assessment (FGA)}

한글화된 FGA는 100 명의 뇌졸중 환자를 대상으로 측정자내 신뢰도 는 2 명의 물리치료사와 2 명의 물리치료학과 학생에 의해 처음 평가한 후 하루 또는 이틀이 지난 다음 두 번째 평가가 이루어졌다. 총점에 대한 측정자내 신뢰도는 급내상관계수 0.92- 0.95로 높은 신뢰도를 나 타냈다. 측정자간 신뢰도를 확인하기 위해서는 먼저 치료사 2 명의 평 가에 대한 일치 정도를 분석하고 이어 치료사 2 명과 학생 2 명이 포함 된 4명의 평가에 대해 일치 정도를 분석하였다. 총점에 대한 치료사 2 명의 측정자간 신뢰도는 급내상관계수 0.95 이었고, 4 명의 측정자간 신뢰도는 0.91 로 높은 신뢰도를 나타냈다. ${ }^{15}$

\section{Rivermead mobility index (RMI)}

한글화된 RMI는 신뢰도와 타당도를 알아보기 위해 37 명의 뇌졸중
환자를 대상으로 1 명의 물리치료사가 측정자내 신뢰도를 조사하기 위해 7 일에 걸쳐 2 번의 평가를 실시했다. 그리고 RMI의 동시 타당도 를 알아보기 위해 처음 검사가 끝난 후 stroke rehabilitation assessment of movement (STREAM), Barthel index (BI) 검사를 시행하였다. 그 결 과 총 점수의 측정자내 신뢰도는 급내상관계수 0.98 로 매우 높은 신 뢰도를 보였고, 동시 타당도 조사에서도 STREAM과 $\mathrm{r}=0.85$ 로 매우 높은 양의 상관관계가 있고, $\mathrm{BI}$ 와는 $\mathrm{r}=0.70$ 으로 높은 양의 상관관계 가 있었다. ${ }^{16}$

\section{Motor assessment scale (MAS)}

한글화된 MAS는 측정자내 신뢰도를 평가하기 위해 무작위로 9명의 환자를 3 주 간격으로 7 명의 물리치료사가 2 번의 평가를 시행 하였다. 측정자내 신뢰도는 1 번 항목 $(\mathrm{ICC}=0.75)$ 과 3 번 항목 $(\mathrm{ICC}=0.79)$ 에서 보통의 신뢰도를 보였고, 다른 항목에서는 모두 높은 신뢰도를 나타 내었다 $(\mathrm{ICC}=0.87-0.99)$. 측정자간 신뢰도를 알아보기 위해 무작위로 20 명의 비디오 파일을 빔 프로젝트를 사용하여, 23 명의 물리치료사 가 각자 독립적으로 평가하였다. 측정자간 신뢰도는 0.99 이상으로 매 우 높은 신뢰도를 나타내었다.17

\section{Tinetti-gait scale}

한글화된 Tinetti-gait scale는 52 명의 뇌졸중 환자를 대상으로 2 명의 물리치료사가 각각 대상자들을 Tinetti-gait scale로 평가하는 동시에 평가를 위한 과제를 수행하는 모습을 비디오로 촬영하였다. 그리고 10 일 뒤에 동일한 치료사 2 명이 대상자들이 과제를 수행하는 모습이 촬영된 비디오를 보고 재평가하였다. 그 결과 총점에 대한 측정자간 신뢰도 급내상관계수 0.91 이었다. 동시 타당도를 조사하기 위해 3 일에 걸쳐 dynamic gait index (DGI), 10MWT, 마비측과 비마비측의 one leg stand test (OLST)와 sit to stand test 그리고 Fugl Meyer-lower extremity (FM-L/E)들을 이용하여 대상자들을 평가하였다. 그 결과 DGI

Table 1. The reliability and validity of Korean version mobility and gait assessment tools

\begin{tabular}{|c|c|c|c|c|}
\hline Assessment tool & Author (Year) & Method & Reliability & Validity \\
\hline DGI & An et al. (2011) & $\begin{array}{l}26 \text { stroke patients } \\
2 \text { physical therapy }\end{array}$ & $\begin{array}{l}\text { Intra-rater reliability } 0.92 \\
\text { Inter-rater reliability } 0.88\end{array}$ & BBS $(r=0.80), 10 M W T(r=-0.76)$, TUG $(r=-0.79)$ \\
\hline $\mathrm{FGA}$ & Won and Yu (2011) & $\begin{array}{l}100 \text { stroke patients } \\
2 \text { physical therapy } \\
2 \text { students }\end{array}$ & $\begin{array}{l}\text { Intra-rater reliability } 0.92-0.95 \\
\text { Inter-rater reliability } 0.91,0.95\end{array}$ & \\
\hline $\mathrm{RMI}$ & Kang et al. (2013) & $\begin{array}{l}37 \text { stroke patients } \\
1 \text { physical therapy }\end{array}$ & Intra-rater reliability 0.98 & STREAM $(r=0.84), \mathrm{BI}(r=0.70)$ \\
\hline MAS & Cha et al. (2013) & $\begin{array}{l}23 \text { stroke patients } \\
23 \text { physical therapy }\end{array}$ & $\begin{array}{l}\text { Intra-rater reliability } 0.75-0.99 \\
\text { Inter-rater reliability } 0.99\end{array}$ & \\
\hline Tinetti-gait Scale & An et al. (2014) & $\begin{array}{l}52 \text { stroke patients } \\
2 \text { physical therapy }\end{array}$ & Inter-rater reliability 0.91 & $\begin{array}{l}\mathrm{DGI}(r=0.78), 10 \mathrm{MWT}(r=0.74), \text { OLST }(r=0.65- \\
0.73), \mathrm{FM}-\mathrm{L} / \mathrm{E}(r=0.67), \mathrm{STS}(r=-0.79)\end{array}$ \\
\hline
\end{tabular}

DGI, dynamic gait index; BBS, Berg balance scale; 10MWT, 10meter walk test, TUG, timed up \& go test; FGA, functional gait assessment; RMI, Rivermead mobility index; STREAM, stroke rehabilitation assessment of movement; BI, Barthel index; MAS, motor assessment scale; OLST, one leg stand test; FM-L/E, Fugl Meyer-lower extremity; STS, sit to stand test. 
$(\mathrm{r}=0.78), 10 \mathrm{MWT}(\mathrm{r}=0.74)$, 마비측과 비마비측의 OLST $(\mathrm{r}=0.65-0.73)$, $\mathrm{FM}-\mathrm{L} / \mathrm{E}(\mathrm{r}=0.67)$ 와는 중간 정도의 양의 상관관계가 있었고 STS $(\mathrm{r}=-$ 0.79)와는 중간 정도의 음의 상관관계가 있었다. ${ }^{18}$

본 연구를 통해 뇌졸중 환자에 한글화된 이동성과 보행 평가도구 들의 신뢰도와 타당도는 높은 것으로 조사되었다(Table 1).

\section{고 찰}

많은 이동성과 보행 평가도구들이 대부분 다른 나라에서 만들어진 평가도구들로 언어적, 문화적 차이로 인해 국내 물리치료사들이 이 동성과 보행 평가를 위해 평가도구를 임상에 적용하는데 어려움이 있다. 현재 한글화된 이동성과 보행 평가도구들이 신뢰도와 타당도 를 검증하여 제시되고 있으나 이에 대한 체계적인 분석이 이루어지 지 않았다. 이에 본 연구의 목적은 뇌졸중 환자에 한글화된 이동성과 보행 평가도구들의 신뢰도와 타당도를 체계적으로 분석하고 제시하 여 임상에서 물리치료사들이 정확한 평가를 위해 활용하고자 한다. 우리는 한글화된 이동성과 보행 평가도구로 5 개 문헌에 자료를 채택 했으며 각각의 평가도구는 다음과 같다.

\section{Dynamic gait index (DGl)}

Shumway-Cook과 Woollacott (1995)에 의해 개발된 dynamic gait index 는 노인의 보행 활동 시 낙상의 위험과 기능적인 안정성을 평가하기 위해 만들어졌다. DGI는 보행의 속도 변화, 보행 하면서 좌우로 고개 돌리기, 보행 하면서 고개를 위 - 아래로 움직이기, 4 개의 계단을 오 르고 내리기 등 8 개 과제의 기능적 보행 척도로 구성되어 있다. 0 에서 3 점으로 4점 척도로 구성되어 있으며 0점은 심한 장애, 3 점은 정상으 로 24 점이 만점이다. 노인 뿐만 아니라 뇌졸중 환자, 전정 장애 환자와 다발성 경화증 환자에서도 높은 신뢰도를 보고하였다. 만성 뇌졸중 환자를 대상으로 한 DGI와 BBS $(\mathrm{r}=0.83), 10 \mathrm{MWT}(\mathrm{r}=-0.73)$ 그리고 $\mathrm{TUG}(\mathrm{r}=-0.77)$ 의 상관관계는 이전 연구 결과와 비슷하였다. ${ }^{19}$

\section{Functional gait assessment (FGA)}

Wrisley 등(2004)은 DGI를 일부 변형하고 항목을 추가하여 FGA를 개 발하였다. FGA는 총 10 개의 항목으로 구성되어 있으며, 구체적인 항 목은 '평평한 지면에서 보행하기', '보행 속도를 변경하기', '보행하면서 옆으로 머리를 돌리기', ‘보행하면서 상하로 머리를 움직이기', ‘보행하 다가 한 발을 축으로 해서 돌기', '장애물 위를 지나 걷기', '좁은 기저면 에서 걷기', '눈을 감고 걷기', '뒤로 걷기', '계단 오르내리기'이다. 각 항 목은 점수를 0 에서 3 점까지 줄 수 있는 4 점 척도이다. 뇌졸중 환자를 대상으로 한 이전 연구에서 측정자내 신뢰도는 0.97 로 높았고, 측정 자간 신뢰도 역시 0.94 로 높게 나타나 뇌졸중 환자를 위한 보행 평가
도구로 받아들이기에 충분한 신뢰도가 있는 것으로 보고되었다.20

\section{Rivermead mobility index (RMI)}

Collen 등(1991)에 의해 개발되고 보완된 RMI는 뇌졸중과 같은 신경 학적 질환을 가진 환자들의 운동성을 평가하는데 높은 신뢰도를 가 진 평가도구로 침대에서 돌아 눕기에서 부터 달리기까지 수준에 따 라 15 개의 항목이 단계별로 구성되어 있으며, 2 점 척도로서 0 점은 평 가 동작을 수행할 수 없는 경우, 1 점은 평가 동작을 수행할 수 있는 경 우로 나뉘어 계산되어 진다. 각 항목의 평가는 평가자와 환자의 문답 형식으로 이루어졌고 5번 항목은 환자가 직접 수행하여 평가하였으 며, 점수가 높을수록 운동성이 좋다는 것을 의미한다. ${ }^{21}$ Tyson과 Con$n \mathrm{ell}^{12}$ 은 뇌졸중을 포함한 신경계 손상 환자에 신뢰도와 타당도 있고 임상적으로 유용한 이동성과 보행 평가 방법으로 RMI을 추천하고 있다.

\section{Motor assessment scale (MAS)}

Carr 등(1985)에 의해 개발된 MAS는 뇌졸중 환자의 기능적 과제 수 행 능력을 평가하기 위한 평가지이다. MAS는 뇌졸중 환자의 잔여 운 동기능을 평가하여 시너지 패턴보다 오히려 기능적 과제의 수행 능 력을 평가하기 때문에 널리 유용하게 사용되고 있다. 바로 누운 자세 에서 비 마비 측으로 눕기, 바로 누운 자세에서 침대 끝에 앉기, 앉은 자세에서 균형 잡기, 앉은 자세에서 일어서기, 보행, 상지 기능, 손 움직 임, 정교한 손 활동으로 총 8 가지 항목으로 구성되어 있다. 각 항목은 7점(0-6) 척도이며 수행 할 수 없을 때 0점에서 최상의 기능 시 최고 6 점 만점으로 이루어지며, 총 48점 만점이다. 현재까지 임상과 관련하 여 신뢰도, 타당도, 통계적 지표를 나타내는 핵심 평가지로서 높은 점 수를 보여주고 있다. ${ }^{22}$ 그러나 상지 기능, 손 움직임 그리고 정교한 손 활동 같은 항목은 이동성과 보행 평가도구와는 상관관계가 떨어지 는 단점을 가지고 있다.

\section{Tinetti-gait scale}

Tinetti (1986)에 의해 개발된 Tinetti-gait scale는 주로 노인의 이동성 및 낙상 위험도를 평가하는데 사용되어 왔는데, 보행 시작, 좌 · 우측 의 보폭, 발을 지면에서 끌지 않고 들기, 보행 대칭성, 보행 연속성, 보 도 통과, 몸통의 안정성, 앞서기 등 총 8 개의 과제로 12 점 만점으로 구 성되어 있다. 뇌졸중 환자에 대한 Tinetti-gait scale측정자간 신뢰도는 급내상관계수 0.91 이었고, 동시 타당도를 조사에서DGI $(r=0.78)$, $10 \mathrm{MWT}(\mathrm{r}=0.74)$, 마비측과 비마비측의 OLST ( $\mathrm{r}=0.65-0.73), \mathrm{FM}-\mathrm{L} / \mathrm{E}$ $(\mathrm{r}=0.67)$ 와는 중간 정도의 양의 상관관계가 있었고 STS $(r=-0.79)$ 와는 중간 정도의 음의 상관관계가 있었다. 따라서 만성 뇌졸중 환자의 보 행 능력을 평가하는데 유용한 평가도구로 사용이 가능할 것이다. ${ }^{23}$ 
본 연구를 통해 뇌졸중 환자에 한글화된 이동성과 보행 평가도구 들의 신뢰도와 타당도는 높은 것으로 조사되었다. 측정자내 신뢰도 는 RMI (0.98), FGA (0.92-0.95), DGI (0.92)가 높았으며, 측정자간 신뢰 도는 MAS (0.99), FGA (0.91, 0.95), Tinetti-gait scale (0.91), DGI (0.88) 순 으로 높았다. 뿐만 아니라 타당도 조사에서도 한글화된 DGI는 BBS $(\mathrm{r}=0.80)$ 와 중등도의 양의 상관관계가 있었고, $10 \mathrm{MWT}(\mathrm{r}=-0.76)$, TUG $(\mathrm{r}=-0.79)$ 와는 음의 상관관계를 보였고, RMI는 동시 타당도 조 사에서 STREAM과 $r=0.85$ 로 매우 높은 양의 상관관계가 있고, BI와 는 $\mathrm{r}=0.70$ 으로 높은 양의 상관관계가 있었다. Tinetti-gait scale는 DGI $(\mathrm{r}=0.78), 10 \mathrm{MWT}(\mathrm{r}=0.74)$, 마비측과 비마비측의 OLST ( $\mathrm{r}=0.65-0.73)$, $\mathrm{FM}-\mathrm{L} / \mathrm{E}(\mathrm{r}=0.67)$ 와는 중간 정도의 양의 상관관계가 있었고 STS ( $\mathrm{r}=-$ 0.79)와는 중간 정도의 음의 상관관계가 있었다.

국내 물리치료사들의 보행 평가에 대한 인식과 실태 조사에서 기 능적 평가도구에 대한 인식과 실태는 높은 편이였으나, 표준화된 평 가도구들의 인식과 실태는 상대적으로 낮았으며, ${ }^{24}$ 균형과 보행 평가 수행에 있어서 장벽들에 대한 연구 또한 평가도구에 대한 지식 부족 과 신뢰도와 타당도 있는 평가도구 선정에 어려움이 중요한 장벽으 로 작용한다고 하였다. ${ }^{25}$ 그러므로 우리는 표준화된 평가도구들에 대 한 더 많은 한글화된 평가도구들의 신뢰도와 타당도 연구가 필요해 보인다.

본 연구의 제한점은 체계적인 문헌 고찰을 통해 자료를 수집하였 으나 electronic databases로 RISS, KISS과 NDSL 그리고 DBpia만을 사 용했으며, 2017년 6월 이후 출간된 문헌과 등재 되지 않은 문헌이나 회색 문헌은 검색하지 못하였다. 아울러 modified Rivermead mobility index (MRMI) 같은 수정된 평가도구 ${ }^{26}$ 와 기능적 동작 수행을 통한 평 가 방법인 $10 \mathrm{MWT}, 6 \mathrm{MWT}$, TUG와 8 자 모양 경로 보행 검사(figure of 8 walk test) ${ }^{27}$ 그리고 four square step test (FSST) ${ }^{28}$ 같은 평가 방법은 배 제한 것이다. 뿐만 아니라 5 개의 문헌만을 분석하여 이전에 한글화된 균형 평가도구에서 9 개 문헌을 바탕으로 한 것 29 에 비해 적은 자료를 바탕으로 한 것 또한 제한점이다.

본 연구를 통해 한글화된 보행 평가도구들의 신뢰도와 타당도는 높은 것으로 나타났다. 이러한 높은 신뢰도와 타당도를 갖는 한글화 된 이동성과 보행 평가도구들은 임상에서 치료사들이 뇌졸중 환자 에 이동성과 보행 능력을 평가하는데 유용하게 사용될 수 있을 것이 다. 그러나 우리는 연구 과정에서 물리치료적 중재에 대한 연구는 많 음에도 불구하고 정확한 평가를 위한 평가도구에 대한 연구는 상대 적으로 적어 평가도구에 대한 더 많은 연구가 필요해 보인다. 앞으로 의 연구는 신뢰도와 타당도 있는 평가도구들을 비교 분석하여 국내 임상 환경에서 사용하기에 가장 적합한 평가도구를 찾고 가이드라 인을 제시하는 것이다.

연구는 체계적인 문헌 고찰을 통해 뇌졸중 환자에 한글화된 이동
성과 보행 평가도구들로 dynamic gait index (DGI), functional gait assessment (FGA), Rivermead mobility index (RMI), motor assessment scale (MAS), Tinetti-gait scale을 확인했고, 그 신뢰도와 타당도를 분석 하였다. 그 결과 한글화된 평가도구들은 높은 신뢰도와 타당도를 갖 고 있었다. 높은 신뢰도와 타당도를 갖는 한글화된 이동성과 보행 평 가도구들은 임상에서 치료사들이 뇌졸중 환자에 이동성과 보행 능 력을 평가하는데 유용하게 사용될 수 있을 것이다.

\section{REFERENCES}

1. Bohannon RW, Williams Andrews A, Smith MB. Rehabilitation goals of patients with hemiplegia. Int J Rehab Research. 1988;11:181-3.

2. Behrman AL, Lawless-Dixon AR, Davis SB et al. Locomotor training progression and outcomes after incomplete spinal cord injury. Phys Ther. 2005;85(12):1356-71

3. Langhorne P, Coupar F, Pollock A. Motor recovery after stroke: a systematic review. Lancet Neurol. 2009;8:741-54.

4. Jung T, Ozaki Y, Lai B et al. Comparison of energy expenditure between aquatic and overground treadmill walking in people post-stroke. Physiother Res Int. 2014;19:55-64.

5. Yu KH, Jeon HS. The effects of dual-task gait training on gait performance under cognitive tasks in chronic stroke. J Kor Phys Ther. 2015;27(5):364-8.

6. Ham SC, Lim CG. The effects of robot-assisted gait training with visual feedback on gait, balance and balance confidence in chronic stroke patients. J Kor Phys Ther. 2016;28(2):71-6.

7. Kim HM, Son SM. Effect of action observation training with auditory feedback for gait function of stroke patients with hemiparesis. J Kor Phys Ther. 2017;29(5):246-54.

8. Horak FB. Clinical assessment of balance disorders. Gait Posture. 1997;6:76-84.

9. Tyson S, DeSouza L. The measurement of balance and walking poststroke. Part 2: functional performance tests. Phys Ther Rev. 2002;7:18791.

10. Tyson S, DeSouza L. A systematic review of methods to measure balance and walking post-stroke. Part 1: ordinal scales. Phys Ther Rev. 2002;7:173-86.

11. Kim BO. Methods in clinical gait analysis. J Korean Acad Rehabil Med. 1994;18:191-202

12. Tyson S, Connell L. The psychometrics properties and clinical utility of measures of walking and mobility in neurological conditions: a systematic review. Clin Rehabil. 2009;23:1018-33.

13. Beaton DE, Bombardier C, Guillemin F et al. Guidelines for the process of cross-cultural adaptation of self-report measures. Spine. 2000;25(24):3186-91.

14. An SH, Seo HD, Chung YJ. Reliability and validity the Korean version of the dynamic gait index in patients with stroke. Journal of Special Education \& Rehabilitation Science. 2011;50:289-306.

15. Won JI, Yu KH. Reliability of the functional gait assessment in patients with stroke. Phys Ther Korea. 2011;18:64-73.

16. Kang HK, Jung KS, Chung YJ. Validity and reliability of the Korean ver- 
sion of Rivermead mobility index in patients with stroke. Journal of Special Education \& Rehabilitation Science. 2013;52:183-96.

17. Cha YR, Jung KS, Chung YJ. Reliability of the Korean version of motor assessment scale in patients with stroke. Journal of Special Education \& Rehabilitation Science. 2013;52:279-93.

18. An SH, Lee DG, Lee YB et al. Inter-rater absolute reliability and concurrent validity of Tinetti-gait scale (Korean version) in stroke patients. J Korean Soc Phys Med. 2014;9(2):201-11.

19. Shumway-Cook A, Woollacott MH. Motor control: theory and practical applications. Baltimore, Williams \& Wilkins, 1995.

20. Wrisley DM, Marchetti GF, Kuharsky DK et al. Reliability, internal consistency, and validity of data obtained with the functional gait assessment. Phys Ther. 2004;84(10):906-18.

21. Collen FM, Wade DT, Robb GF et al. The Rivermead mobility index: a further development of the Rivermead motor assessment. Int Disabil Stud. 1991;13(2):50-4.

22. Carr JH, Shepherd RB, Nordholm L et al. Investigation of a new motor assessment scale for stroke patients. Phys Ther. 1985;65(2):175-80.

23. Tinetti ME. Performance oriented assessment of mobility problems in elderly patients. J Am Geriatr Soc. 1986;34(2):119-26.

24. Jang HY, Kim YL, Kim SJ et al. Perception and use of gait measures among physical therapists in South Korea. Phys Ther Rehabil Sci. 2017;6(2):90-5.

25. Jang HY, Kim YL, Oh JL et al. Barriers to using balance and gait assessment tools by physical therapists in patients with neurological impairments: a systematic review. J Clin Res Bioeth. 2017;8(4):309-14.

26. An SH, Lee GC, Lee KB et al. The inter-rater reliability and concurrent validity of the modified Rivermead mobility index for stroke survivors. Journal of Special Education \& Rehabilitation Science. 2016;55:277-95.

27. Park CS. The inter-rater absolute reliability and validity of the figure of 8 walk test in patients with chronic stroke. J Korea Acad Industr Coop Soc. 2017;18(5):467-74.

28. Park CS, An SH. The reliability and validity of the four square step test in stroke patients. Journal of Special Education \& Rehabilitation Science. 2017;56:309-25.

29. Jang HY, Lee JH, Lee SM. The analysis on the reliability and validity of Korean-version balance assessment tools. J Korean Soc Phys Med. 2017;12(4):139-46 